\title{
Measurement of airway hyperresponsiveness: new considerations
}

\author{
Jan Lötvall, Mark Inman, Paul O’Byrne
}

Since its initial descriptions in $1946,{ }^{1}$ the measurement of airway responsiveness with inhaled bronchoconstrictor stimuli such as methacholine or histamine has become routine practice in the diagnosis and follow up of asthmatic patients. Practically, this involves the patient inhaling increasing doses or concentrations of a stimulus until a given level of bronchoconstriction is achieved, typically a $20 \%$ fall in forced expired volume in one second $\left(\mathrm{FEV}_{1}\right)$. Airway responsiveness is then expressed as the provocative dose or concentration of the stimulus required to achieve this degree of bronchoconstriction $\left(\mathrm{PD}_{20}\right.$ and $\mathrm{PC}_{20}$, respectively).

\section{Definition of terms}

The term "airway responsiveness" is preferred when discussing $\mathrm{PD}_{20}$ and $\mathrm{PC}_{20}$ measurements as this is a non-specific term that encompasses the underlying mechanisms that may be responsible for differences in these measurements either between individuals or within an individual over time ${ }^{2}$. This is best illustrated in fig 1 where it can be seen that a decrease in $\mathrm{PC}_{20}$ may be due to a steeper dose-response curve (hyperreactivity) or to a shift in the curve to the left (hypersensitivity), or both. Thus, when an individual displays a decreased $\mathrm{PC}_{20}$ it is usually not known whether this is due to hyperreactivity or hypersensitivity although it is certainly one, the other, or both-all of which are covered by the term airway "hyperresponsiveness".

\section{Airway responsiveness in asthma}

Airway hyperresponsiveness (AHR) is present in almost all patients with asthma, at least when they are having current symptoms. ${ }^{3}$ Furthermore, it is well established that patients with more severe asthma have more responsive airways than patients with mild disease, ${ }^{3-6}$ and that patients experiencing exacerbations of asthma-for example, during allergen exposure-develop more pronounced AHR during this period. ${ }^{4}$

The difference in airway responsiveness between normal individuals and asthmatic patients is substantial ${ }^{3}$ being $4-8$ doubling concentrations of inhaled methacholine less than in those normal subjects in whom it can be measured. In fact, no identifiable airway responsiveness can be measured in many healthy individuals as $\mathrm{FEV}_{1}$ does not fall by $20 \%$ (fig 2A). However, in individual asthmatic patients airway responsiveness is generally quite stable when the disease is stable, but can increase during exacerbations of asthma induced by allergen or other stimuli (fig 2B).
The aim of the present review is to discuss the association between allergen induced changes in airway responsiveness and other markers of disease severity including symptoms and inflammatory indices. Following a short discussion of the possible mechanisms responsible for airway hyperresponsiveness, we will examine changes in responsiveness associated with natural allergen exposure as well as experimental allergen challenges with both high and low doses of allergen, and how these changes in AHR correlate with changes during the clinical course of asthma. An important focus of this review will thus be to establish whether experimental increases in AHR as a result of allergen challenge are clinically relevant. Finally, we will discuss which practical issues we regard to be important when designing allergen challenge based studies and when interpreting studies already published.

\section{Mechanisms of AHR}

Many different factors have been suggested to be involved in the AHR seen in asthma. Fundamentally different inflammatory processes are thought to be important. It is believed that the increased number of eosinophils in asthmatic airways produces many of the tissue changes seen in the disease, including epithelial damage, thickening of the basement membrane, and the release of mediators with the capacity to cause bronchial smooth muscle contraction and exudation of plasma, resulting in thickening of the airway wall. Indeed, it is possible that a number of these different mechanisms interact to produce AHR, but it seems that different mechanisms are involved in causing different components of AHR. Firstly, it is likely that one separate mechanism is responsible for the underlying hyperresponsiveness in asthmatic patients, differentiating them from normal individuals. Secondly, another mechanism seems to be important for the changes in AHR seen within asthmatic subjects during the course of the disease.

MECHANISM OF THE UNDERLYING AHR

It seems plausible that the airway wall thickening seen in asthma could explain some of the differences in AHR between normal individuals and asthmatic patients. For example, it has been reported that the thickness of the airway wall from necropsy specimens is greater in subjects with fatal asthma than in those with milder disease and in non-asthmatics. ${ }^{8}$ It is not exactly clear which tissue contributes most to thickening of the airway wall in asthma, but the subepithelial thickening seen in bronchial biopsy specimens from most asthmatics ${ }^{9}$ may be involved. Furthermore, the bronchial
Received 15 December 1997 Accepted for publication 18 December 1997 


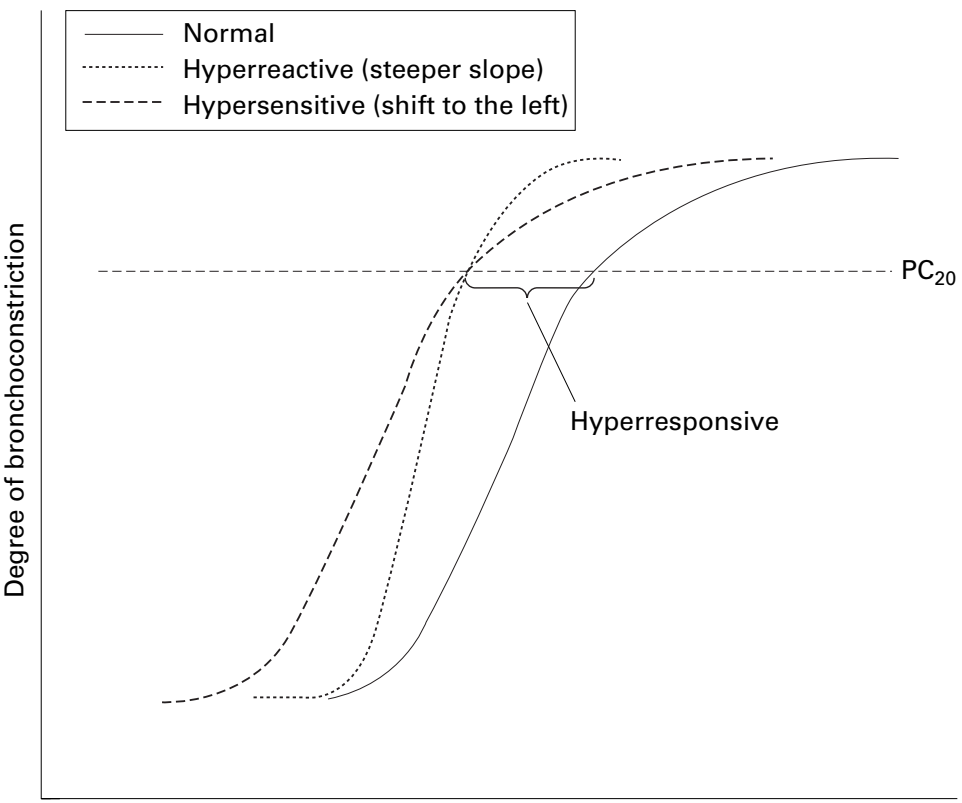

Dose of bronchoconstrictor stimuli

Figure 1 Changes in FEV, induced by increasing doses of a bronchoconstrictor stimulus such as histamine or methacholine. Bronchial hyperresponsiveness, defined as the dose causing a $20 \%$ fall in $F E V_{1}$, can be induced by airway hypersensitivity (shift to the left of the dose-response curve) or airway hyperreactivity (steeper slope of the dose-response curve). This figure illustrates how either of these two different mechanisms may result in the same degree of hyperresponsiveness (as measured by a shift in $P C_{20}$ ).

smooth muscle may have a larger volume in asthmatic subjects, at least in patients with more severe disease. Lastly, exudation of plasma can cause oedema, and thus thickening, of the airway wall. ${ }^{10-13}$ Together these factors may, by geometric mechanisms, enhance the airway luminal resistance induced by a certain degree of airway smooth muscle shortening. ${ }^{14}$ Another feature of the asthmatic airway that correlates with the degree of AHR is loss of epithelial structure ${ }^{15}$ or the appearance of epithelial cells in bronchoalveolar lavage fluid. ${ }^{16}$ The partial loss of the epithelial barrier may allow greater amounts of bronchoconstrictor mediators to reach the smooth muscle or other cells which amplify the bronchoconstricting effect of the inhaled mediators. Alternatively, the release of bronchodilating substances from the epithelium ${ }^{17}$ could be reduced in states of epithelial damage which could enhance bronchial smooth muscle contraction induced by inhaled or endogenous bronchoconstrictor stimuli. One such epithelial bronchodilating factor is $\mathrm{PGE}_{2}{ }^{18}{ }^{19}$ but it seems that non-prostanoid factors are also involved.

MECHANISM OF CHANGES IN AHR

Bronchial wall eosinophilic inflammation is a prominent feature of asthma and it has been suggested that chronic eosinophilic inflammation contributes to the development of a persistent AHR by mechanisms of inducing airway wall thickening. However, it seems unlikely that ongoing eosinophilic inflammation by itself would be the sole cause of AHR because eliminating the inflammation by glucocorticoids only improves, but does not eliminate, AHR. ${ }^{20}$ However, fluctuations in the extent of eosinophilic inflammation may underlie the changes in AHR seen during the course of the disease. The number of eosinophils, as well as their activation as judged by surface EG2 staining in bronchial biopsy specimens and lavage fluid from asthmatic subjects, correlated inversely with AHR. ${ }^{21}$ Furthermore, different forms of allergen exposure such as challenge with a single dose of allergen, ${ }^{22-24}$ exposure to repeated low doses of allergen, ${ }^{25}{ }^{26}$ or seasonal exposure to a pollen allergen, ${ }^{27}$ all of which increase eosinophilic airway inflammation as judged by biopsy specimens, lavage fluid or induced sputum, enhance the AHR that is already present in these individuals. Furthermore, eliminating or decreasing allergen load by allergen avoidance measures only improves, but does not eliminate, $\mathrm{AHR}^{28-30}$

While we have proposed that there may be separate mechanisms responsible for the underlying AHR of asthma and for the fluctuations seen throughout the course of the disease, it is quite likely that this distinction is not complete. Clearly it is possible, if not probable, that the underlying mechanisms responsible for inflammatory cell recruitment and mediator release may, in the short term, be responsible for fluctuations in AHR and, in the long term, for the underlying structural changes responsible for chronic AHR.

\section{AHR AND OTHER ASTHMA VARIABLES}

AHR has been shown to increase during natural exacerbations of asthma. Increased variability of peak expiratory flow and symptoms of asthma are generally associated with histamine or methacholine AHR. ${ }^{31-33}$ Furthermore, inducing a slight worsening of asthma by withdrawing inhaled glucocorticoids ${ }^{34}$ increases mean peak expiratory flow variability from approximately $12 \%$ to $18 \%$, which is associated with an increase in methacholine AHR of approximately one doubling dose. This experimental asthma exacerbation was also shown to be associated with increased numbers of both circulating and sputum eosinophils, suggesting a worsening of airway inflammation which may explain the increase in responsiveness.

One intrinsic problem with quantifying AHR during an exacerbation of asthma is, however, that airway calibre may be reduced per se which would increase the AHR measured by purely geometric mechanisms. ${ }^{32}$ Changes in AHR in more severe exacerbations of asthma, causing overt changes in lung function, cannot therefore be quantified accurately.

\section{Changes in AHR during natural exposure to allergen}

Natural exposure to allergen includes seasonal pollen inhalation and house dust mite inhalation. The first study to show increases in AHR in asthmatic subjects during seasonal allergen exposure was published by Altounyan in 1979. ${ }^{35}$ The degree of increase in AHR with natural allergen exposure varies between patients and probably with the dose of exposure, but in a population of asthmatics the mean 

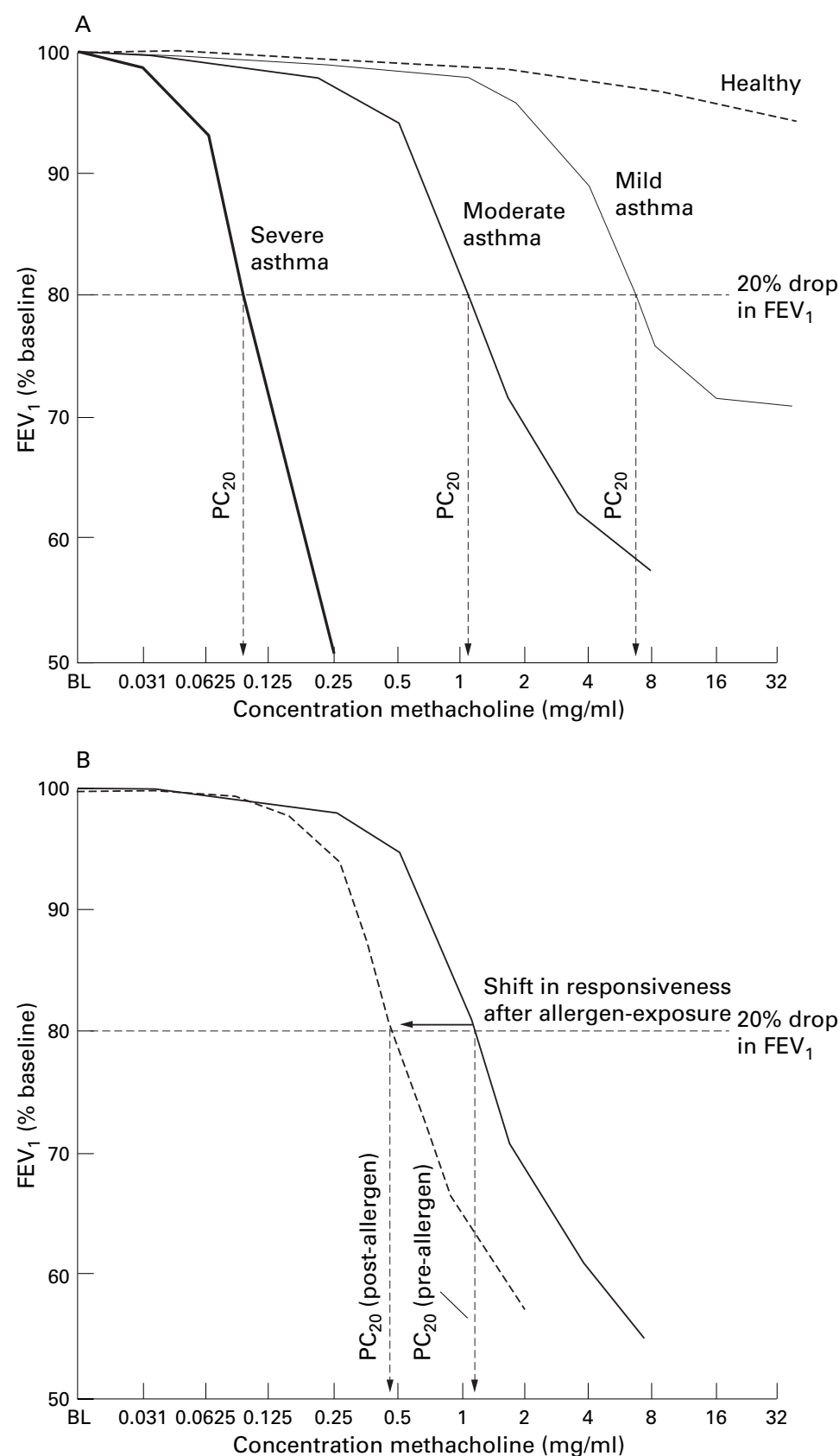

Figure 2 (A) Change in FEV versus baseline induced by increasing doses of a bronchoconstrictor stimulus (methacholine) in mild, moderate, and severe asthmatics compared with healthy individuals. The $P C_{20}$ value is calculated by interpolating a $20 \%$ fall in FEV to the log linear dose-response curve for each individual. Mild asthmatic patients respond at high doses of methacholine, most often showing evidence of a plateau of the dose-response curve. By contrast, moderate and severe asthmatic subjects respond with bronchoconstriction at much lower doses and, in the most severe cases, no plateau of the dose-response curve can be found. (B) The degree of shift in bronchial hyperresponsiveness in an asthmatic individual having been exposed to allergen is on a mean level approximately 1-2 doubling doses of methacholine/histamine. This degree of shift is much smaller than the difference seen between asthmatic patients and normal individuals $(A)$.

changes in AHR to cholinergic stimuli are of the magnitude of 1-2 doubling doses. ${ }^{27}{ }^{35-38}$ Based on these observations which show that certain features of asthma are worsened following allergen exposure, a number of experimental studies have been performed with experimental allergen challenges. These studies have in many ways increased our understanding of the underlying mechanisms of asthma, and contributed to the development of drugs useful in the management of asthma.
CHANGES IN AHR AFTER SINGLE ALLERGEN EXPOSURE

The first published study to demonstrate increased AHR following single dose airway allergen challenge was by Cockcroft et al. ${ }^{4}$ In this study the increased histamine AHR following allergen challenge was found to last for up to seven days and was more likely to occur in subjects who developed dual asthmatic responses (early and late bronchoconstriction) than in isolated early responders, a finding which has been supported by several subsequent studies. $^{39-41}$ In a recent study involving 31 asthmatic subjects we have measured an average shift in methacholine $\mathrm{PC}_{20}$ of 1.39 doubling concentrations 24 hours after a single dose allergen challenge, producing early and late asthmatic responses reflected by at least $15 \%$ falls in $\mathrm{FEV}_{1}{ }^{42}$ The increase in AHR after allergen inhalation challenge has been associated with increases in a number of markers of airway inflammation including circulating levels of eosinophils, eosinophil cationic protein (ECP), and basophils, ${ }^{39} 43$ bronchoalveolar lavage fluid levels of activated eosinophils and lymphocytes, ${ }^{22} 234445$ and levels of eosinophils, neutrophils and metachromatic cells in induced sputum. ${ }^{24647}$

CHANGES IN AHR DURING REPEATED LOW DOSE ALLERGEN EXPOSURE

A number of studies with experimental low dose allergen exposure in mild asthmatic subjects have recently been reported..$^{25} 26$ These studies have all been performed in patients with asthma symptoms associated only with allergen exposure. In two of the reported studies the dose of allergen was individualised on the basis of the patient's sensitivity to allergen and a dose of 5-25\% of the dose causing an early and late asthmatic response was generally used (greater than $15 \%$ decrease in $\mathrm{FEV}_{1}$ ), given on 4-7 consecutive days, whereas a randomly chosen low dose was selected for the older study. ${ }^{48}$

These studies suggest that methacholine AHR increases after repeated low dose allergen exposure. It had been argued that this change in AHR was unaccompanied by increased inflammation. ${ }^{48}$ However, in two more recent studies increased plasma levels of ECP and airway sputum eosinophilia were associated with the increased airway responsiveness. ${ }^{25} 26$ In these studies the degree of increase in AHR depended on the time of measurement. A maximal change was observed eight hours after the third low dose allergen exposure and amounted to approximately two doubling doses compared with repeated placebo/vehicle. ${ }^{26}$ This degree of change in AHR was maintained for at least another two days of low dose allergen exposure. ${ }^{26}$ The increase in AHR induced by low dose allergen exposure seems to recover to basal levels quite rapidly and 24-30 hours after the last dose the observed degree in change was only approximately one doubling dose, ${ }^{25} 26$ and 72 hours later the induced changes in AHR were no longer statistically significant. ${ }^{26}$ 
In these two recent studies it was clearly shown that repeated exposure to low dose allergen causes both symptoms of asthma ${ }^{25} 26$ and increased variability in lung function, ${ }^{25}$ suggesting that experimentally increasing AHR by approximately $1.5-2$ doubling doses is associated with signs of clinical worsening of asthma.

CLINICAL RELEVANCE OF INDUCED CHANGES IN AHR

The reviewed studies suggest that exposure to a single allergen, to repeated low dose allergen, to natural allergen and spontaneously occurring exacerbations of asthma all enhance methacholine or histamine AHR by, on average, 1-2 doubling doses from a stable baseline. These changes in AHR are likely to be clinically significant since they occur in addition to the persisting AHR that is present in all asthmatic subjects and are associated with increases in variability of lung function and symptoms of asthma.

It has been suggested that indirect challenges such as isocapnic dry air hyperventilation, exercise, or inhalation of adenosine monophosphate (AMP) would illustrate the inflammatory state of the airways better than methacholine or histamine challenges. ${ }^{49-51}$ It is therefore possible that different challenge methods may be used to understand different aspects of the underlying mechanisms of the change in AHR induced by allergen exposure.

MEASURING ALLERGEN INDUCED AHR

The proven association between allergen induced AHR and allergen induced inflammation supports the many studies where the efficacy of several classes of anti-asthma drugs has been tested by their ability to prevent increases in AHR following allergen inhalation challenge. ${ }^{52-63}$ To date all investigations of this type have been based on the single allergen challenge protocol. Typically, in these studies sample sizes ranging from eight to 20 subjects are used in a repeated measures crossover design to test for differences between treated and placebo responses.

We have recently performed a series of power calculations to determine whether these sample sizes are adequate for investigating treatment effects on allergen induced airway responses. When doing this we have assumed that a treatment induced reduction of $50 \%$ in any allergen induced deterioration in asthma is clinically significant (including early and late asthmatic responses and changes in airway responsiveness). Based on this assumption we have previously shown that sample sizes of approximately 10 subjects are sufficient to demonstrate clinically significant effects $(50 \%$ attenuation) on the magnitude of both the early and late asthmatic responses. ${ }^{64}$ More recently, however, we have evaluated what would be the appropriate sample sizes to determine the efficacy of various treatments on allergen induced increases in airway responsiveness. ${ }^{42} I n$ this study 31 subjects with dual asthmatic responses following airway allergen challenge showed a mean fall in methacholine $\mathrm{PC}_{20}$ of
1.29 doubling concentrations. In the same study we calculated the average standard deviation of the difference between placebo and actively treated $\mathrm{PC}_{20}$ shifts in several published trials and found it to be 0.96 doubling concentrations. Based on these observations we calculated the number of subjects required to demonstrate clinically significant effects on allergen induced AHR (50\% attenuation) in repeated measures trials. Assuming a desired power level of $90 \%$ we found that 24 subjects would be required to demonstrate, with a $90 \%$ power, that a treatment can attenuate allergen induced AHR by $50 \%$. Obviously fewer subjects would be required when studying more effective treatments, but it is clear that sample sizes currently employed in studies of this type are inadequate, resulting in low power to show inhibitory effects on allergen induced AHR.

While there have been few studies to date quantifying the changes in AHR following multiple low dose allergen challenge, it is clearly important that appropriate sample size requirements should be established before this protocol becomes widely used to test the efficacy of anti-asthma drugs. Based on our initial study with eight subjects we have observed an average increase shift in $\mathrm{PC}_{20}$ of 1.72 doubling concentrations with a standard deviation of 0.32 doubling concentrations in the difference between the allergen and diluent conditions. Assuming that this standard deviation will be close to that measured when comparing allergen responses following active treatment and placebo, drugs resulting in a $50 \%$ attenuation of the allergen induced shift in $\mathrm{PC}_{20}$ could be detected with fewer than five subjects ( $90 \%$ power). This higher power of the repeated low dose challenge compared with the more widely used single high dose challenge clearly needs to be further investigated before studies are performed with such small sample sizes.

\section{Conclusion}

Inhaled allergens initiate processes that increase airway inflammation and enhance AHR in asthmatic subjects. Thus, studies using inhaled allergen challenges have provided insight into how changes in AHR are regulated by induced inflammatory processes. These changes in AHR (1-2 doubling doses) have been shown to be of much smaller magnitude than those seen when asthmatics with stable AHR are compared with normal subjects in whom AHR can be measured (differences of 4-8 doubling doses). These allergen induced changes are, however, important as they are similar to changes occurring in asthmatic subjects who already have AHR that are associated with worsening asthma control. It is likely that the mechanisms responsible for the changes in AHR following experimental allergen exposure are similar to those producing transient worsening of control in asthmatics. Nevertheless, the mechanisms of the transient allergen induced AHR are not likely to explain the underlying mechanisms of the persistent AHR 
in asthmatic patients when compared with normal individuals.

JL is financed by the Vårdal Foundation and the Swedish Medical Research Council

1 Curry JJ. The action of histamine on the respiratory tract in normal and asthmatic subjects. $\mathcal{F}$ Clin Invest 1946;25:78591.

2 Sterk PJ. Bronchial hyperresponsiveness: definition and terminology. Pediatr Allergy Immunol 1996;7(Suppl 9):7-9.

3 Cockcroft DW. Airway responsiveness. In: Barnes PJ Grunstein MM, Leff AR, Woolcock AJ, eds. Asthma. Philadelphia: Lippincott-Raven, 1997: 1253-66.

4 Cockcroft DW, Ruffin RE, Dolovich J, Hargreave FE. Allergen-induced increase in non-allergic bronchial reactivity. Clin Allergy 1977;7:503-13.

5 Murray AB, Ferguson AC, Morrison B. Airway responsiveness to histamine as a test for overall severity of asthma in children. F Allergy Clin Immunol 1981;68:119-24.

6 Boushey HA, Holtzman MJ, Sheller JR, et al. Bronchial hyperreactivity. Am Rev Respir Dis 1980;121:389-413.

7 Cartier A, Thomson NC, Frith PA, et al. Allergen-induced increase in bronchial responsiveness to histamine: relationship to the late asthmatic response and change in airway caliber. F Allergy Clin Immunol 1982;70:170-7.

8 Carroll N, Elliot J, James A. The structure of the large and small airways in nonfatal and fatal asthma. Am Rev Respir Dis 1993;147:405-10.

9 Jeffery PK, Godfrey RW, Adelroth E, et al. Effects of treatment on airway inflammation and thickening of basement membrane reticular collagen in asthma. A quantita-
tive light and electron microscopic study. Am Rev Respir Dis tive light and electror

10 Lötval J, Lemen RJ, Hui KP, et al. Airflow obstruction after substance $\mathrm{P}$ aerosol: contribution of airway and pulmonary edema. F Appl Physiol 1990;69:1473-8.

11 Persson CG. Role of plasma exudation in asthmatic airways. Lancet 1986;ii:1126-9.

12 Tokuyama K, Lötval J, Barnes PJ, et al. Mechanisms of airway narrowing caused by inhaled platelet-activating factor. Role of airway microvascular leakage. Am Rev Respir Dis 1991;143:1345-9.

13 Chung KF, Rogers DF, Barnes PJ, et al. The role of increased airway microvascular permeability and plasma increased airway microvascular permeability and

14 Hogg JC, Pare PD, Moreno R. The effect of submucosal edema on airways resistance. Am Rev Respir Dis 1987;135: s54-6.

15 Jeffery PK, Wardlaw AJ, Nelson FC, et al. Bronchial biopsies in asthma. An ultrastructural, quantitative study and correlation with hyperreactivity. Am Rev Respir Dis 1989;140: 1745-53.

16 Beasley R, Roche WR, Roberts JA, et al. Cellular events in the bronchi in mild asthma and after bronchial provocation. Am Rev Respir Dis 1989;139:806-17.

17 Flavahan NA, Aarhus LL, Rimele TJ, et al. Respiratory epithelium inhibits bronchial smooth muscle tone. F Appl Physiol 1985;58:834-8.

18 Stuart-Smith K, Vanhoutte PM. Arachadonic acid evokes epithelium-dependent relaxations in canine airways. $\mathcal{F} A p p$ Physiol 1988;65:2170-80.

19 Ullman A, Ciabattoni G, Löfdahl CG, et al. Epitheliumderived PGE2 inhibits the contractile response to cholinerderived PGE2 inhibits the contractile response to choliner-
gic stimulation in isolated ferret trachea. Pulmonol Pharmacol 1990;3:155-60.

20 Lundgren R, Söderberg M, Hörstedt P, et al. Morphological studies of bronchial mucosal biopsies from asthmatics before and after ten years of treatment with inhaled steroids. Eur Respir F 1988;1:883-9.

21 Woolley KL, Adelroth E, Woolley MJ, et al. Granulocytemacrophage colony-stimulating factor, eosinophils and eosinophil cationic protein in subjects with and without mild, stable, atopic asthma. Eur Respir F 1994;7: 1576-84.

22 Aalbers R, Kauffman HF, Vrugt B, et al. Allergen-induced recruitment of inflammatory cells in lavage 3 and $24 \mathrm{~h}$ after challenge in allergic asthmatic lungs. Chest 1993;103:117884.

23 Brusasco V, Crimi E, Gianiorio P, et al. Allergen-induced increase in airway responsiveness and inflammation in mild increase in airway responsiveness and inflam

24 Pin I, Freitag AP, O'Byrne PM, et al. Changes in the cellular profile of induced sputum after allergen-induced asthmatic responses. Am Rev Respir Dis 1992;145:1265-9.

25 Palmqvist M, Petterson K, Sjöstrand M, et al. Variability of lung function during repeated low-dose allergen exposure in mild asthmatics. Am F Respir Crit Care Med 1997;155: A883.

26 Sulakvelidze I, Inman MD, Rerecich T, et al. Increases in airway eosinophils and interleukin- 5 with minimal bronchoconstriction during repeated low dose allergen chal-
lenge in atopic asthmatics. Eur Respir 71998 (in press).

27 Djukanovic R, Feather I, Walls A, et al. Effect of natural allergen exposure during the grass pollen season on inflammatory cells and asthma symptoms. Thorax 1996;51:575matory

28 Platts-Mills TA, Tovey ER, Mitchell EB, et al. Reduction of bronchial hyperreactivity during prolonged allergen avoidance. Lancet 1982;ii:675-8.
29 Peroni DG, Boner AL, Vallone G, et al. Effective allergen avoidance at high altitude reduces allergen-induced bronchial hyperresponsiveness. Am $\mathcal{f}$ Respir Crit Care Med 994;149:1442-6.

30 van Velzen E, van den Bos J-W, Benckhuijsen JAW, et al. Effect of allergen avoidance at high altitude on direct and indirect bronchial hyperresponsiveness and markers of inflammation in children with allergic asthma. Thorax 1996;51:582-4.

31 Brand PRL, Postma DS, Kerstjens HAM, et al. Relationship of airway hyperresponsiveness to respiratory symptoms and diurnal peak flow variations in patients with obstructive lung disease. Am Rev Respir Dis 1991;143:916-21.

32 Ryan G, Latimer KM, Dolovich J, et al. Bronchial responsiveness to histamine: relationship to diurnal variation of peak flow rate, improvement after bronchodilator, and airway calibre. Thorax 1982;37:423-9.

33 Josephs LK, Gregg I, Mullee MA, et al. Nonspecific bronchial reactivity and its relationship to the clinical expression of asthma. A longitudinal study. Am Rev Respir Dis 1989;140:350-7.

34 Gibson PG, Wong BJ, Hepperle MJ, et al. A research method to induce and examine a mild exacerbation of asthma by withdrawal of inhaled corticosteroid. Clin Exp Allergy 1992;22:525-32.

35 Altounyan REC. Changes in histamine and atropine responsiveness as a guide to diagnosis and evaluation of therapy in obstructive airway disease. In: Pepys J, Frankland AW, eds. Disodium cromoglycate in allergic 1970: 47 .

36 Boulet LP, Cartier A, Thompson NC, et al. Asthma and increases in non-allergic bronchial responsiveness from seasonal pollen exposure. f Allergy Clin Immunol 1983;71: 399-406.

37 Sotomayor H, Badier M, Vervloet D, et al. Seasonal increase of carbachol airway responsiveness in patients allergic to grass pollen. Reversal by corticosteroids. Am Rev Respir Dis 1984;130:56-8.

38 Löwhagen O, Rak S. Modification of bronchial hyperreactivity after treatment with sodium cromoglycate during pollen season. F Allergy Clin Immunol 1985;75:460-7.

39 Gibson PG, Manning PJ, O'Byrne PM, et al. Allergeninduced asthmatic responses. Relationship between increases in airway responsiveness and increases in circulating eosinophils, basophils and their progenitors. Am Rev Respir Dis 1991;143:331-5.

40 Cockcroft DW, Murdock KY. Changes in bronchial responsiveness to histamine at intervals after allergen challenge. Thorax 1987;42:302-8.

41 Violante B, Pellegrino R, Crimi E, et al. Increase in airway responsiveness and effect of deep inhalation on airway calber in allergen-induced asthma. Relationship to the late-phase response. Am Rev Respir Dis 1992;146:127-31.

2 Inman MD, Hamilton AI, Kerstjens HAM, et al. The utility of methacholine airway responsiveness measurements in evaluating anti-asthma drugs. F Allergy Clin Immunol 1998 (in press).

43 Pedersen B, Dahl R, Larsen BB, et al. The effect of salmeterol on the early- and late-phase reaction to bronchial allergen and postchallenge variation in bronchial reactivity, blood eosinophils, serum eosinophil cationic protein, and serum eosinophil protein X. Allergy 1993;48: 377-82.

44 Gratziou C, Carroll M, Montefort S, et al. Inflammatory and T-cell profile of asthmatic airways 6 hours after local allergen provocation. Am $\mathcal{F}$ Respir Crit Care Med 1996;153: 515-20.

45 Woolley KL, Ädelroth E, Woolley MJ, et al. Effects of allergen challenge on eosinophils, eosinophil cationic protein and granulocyte-macrophage colony stimulating factor in mild asthma. Am J Respir Crit Care Med 1995;151:191524

46 Fahy JV, Liu J, Wong H, et al. Analysis of cellular and biochemical constituents of induced sputum after allergen challenge: a method for studying allergic airway inflammation. F Allergy Clin Immunol 1994;93:1031-9.

47 Wong BJ, Dolovich J, Ramsdale EH, et al. Formoterol compared with beclomethasone and placebo on allergeninduced asthmatic responses. Am Rev Respir Dis 1992;146: $1156-60$.

48 Ihre E, Zetterström O. Increase in non-specific bronchial responsiveness after repeated inhalation of low doses of allergen. Clin Exp Allergy 1993;23:298-305.

49 O'Byrne PM, Ramsdale EH, Hargreave FE. Isocapnic hyperventilation for measuring airway hyperresponsiveness in asthma and in chronic obstructive pulmonary disease. Am Rev Respir Dis 1991;143:1444-5.

50 Holgate ST, Mann JS, Cushley MJ. Adenosine as a bronchoconstrictor mediator in asthma and its antagonism by methylxanthines. F Allergy Clin Immunol 1984;74: 302-6.

51 Mann JS, Holgate ST, Renwick AG, et al. Airway effects of purine nucleosides and nucleotides and release with bronchial provocation in asthma. F Appl Physiol 1986;61:166776.

52 Boulet LP, Latimer KM, Roberts RS, et al. The effect of atropine on allergen-induced increases in bronchial responsiveness to histamine. Am Rev Respir Dis 1984;130: 368-72.

53 Cockcroft DW, Murdock KY. Comparative effects of inhaled salbutamol, sodium cromoglycate, and beclomethasone dipropionate on allergen-induced early asthmatic responses, late asthmatic responses, and increased bron- 
chial responsiveness to histamine. $\mathcal{F}$ Allergy Clin Immunol 1987;79:734-40

54 Cockcroft DW, Murdock KY, Gore BP, et al. Theophylline does not inhibit allergen-induced increase in airway responsiveness to methacholine. F Allergy Clin Immunol 1989;83:913-20

55 Taylor G, Walker J, Twentyman OP, et al. Protection against allergen-induced asthma by salmeterol. Clin Allergy 1990; 336: $1338-42$.

56 Twentyman OP, Finnerty J, Harris A, et al. Protection against allergen-induced asthma by salmeterol. Lancet 1990;336: $1338-42$

57 Hui KP, Taylor IK, Taylor GW, et al. Effect of a 5-lipoxygenase inhibitor on leukotriene generation and airway responses after patients. Thorax 1991;46:184-9.

58 Taylor IK, O'Shaughnessy KM, Fuller RW, et al. Effect of cysteinyl leukotriene receptor antagonist ICI 204,219 on
allergen-induced bronchoconstriction and airway hyperreactivity in atopic subjects. Lancet 1991;337:690-4.
59 Cockcroft DW, McParland CP, O'Byrne PM, et al. Beclamethasone given after the early asthmatic response inhibits the late response and the increased methacholine reponsiveness. F Allergy Clin Immunol 1993;91:1163-8.

60 Crimi E, Violante B, Pellegrino R, et al. Effect of multiple doses of nedocromil sodium given after allergen inhalation in asthma. F Allergy Clin Immunol 1993;92:777-83.

61 Freitag A, Watson RM, Matsos G, et al. Effect of a platelet activating factor antagonist, WEB 2086, on allergen induced asthmatic responses. Thorax 1993;48:594-8.

62 Hamilton AL, Watson RM, Wylie G, et al. Attenuation of early and late phase allergen-induced bronchoconstriction in asthmatic subjects by a 5-lipoxygenase activating protein antagonist, BAYx 1005. Thorax 1997;52:348-354.

63 Manning PJ, Stevens WH, Cockcroft DW, et al. The role of thromboxane in allergen-induced asthmatic responses. Eur Respir F 1991;4:667-72.

64 Inman MD, Watson R, Cockcroft DW, et al. Reproducibility of allergen-induced early and late asthmatic responses. $\mathcal{F}$ of allergen-induced early and late asthin
Allergy Clin Immunol 1995;95:1191-5. 